\title{
Spatial distribution of frequency modulated signals in Uyo, Nigeria
}

\author{
UJ Ekah ${ }^{1, *}$, AO Adeniran ${ }^{2}$ and OE Shogo ${ }^{3}$ \\ ${ }^{1}$ Department of Physics, Cross River University of Technology, Calabar, Nigeria. \\ 2 Department of Physics, University of Uyo, Uyo, Nigeria. \\ ${ }^{3}$ Department of Science Laboratory Technology, Federal Polytechnic, Offa, Nigeria.
}

World Journal of Advanced Engineering Technology and Sciences, 2022, 05(01), 039-046

Publication history: Received on 20 December 2021; revised on 27 January 2022; accepted on 29 January 2022

Article DOI: https://doi.org/10.30574/wjaets.2022.5.1.0027

\begin{abstract}
The kernel of this study is to x-ray the extent of radio coverage of two Frequency Modulated (FM) radio stations (AKBC 90.5 MHz and Passion FM 94.5MHz), both located in Uyo, Nigeria. Measurement of signal strengths were carried out across 14 locations using a digital spectrum analyzer. A GPS app was used to take measurements of distance, elevation, longitude and latitude. The collected data was analyzed in the form of scattered plot, contour plots, bar charts, graphs and correlation analysis. For AKBC, good reception was received by users at locations N, C, L, and F. For Passion FM, excellent reception was obtained at locations N, F, A and B. For both stations under investigation, location $\mathrm{N}$ had the best reception while location $\mathrm{E}$ had poor reception. To establish the effects of Line of Sight (LOS) distance on signal strength, correlation values of -0.84 and - 0.67 were obtained for AKBC and Passion FM. For signal strength against elevation, 0.71 and 0.55 were the correlation values obtained for AKBC and Passion FM. This shows that an increase in distance from the transmitting antenna led to a decrease in reception while an increase in elevation led to an increase in reception. Existing and intending radio stations in Uyo, are advised to increase the height of their transmitter and transmitting power for better reception and coverage.
\end{abstract}

Keywords: Coverage; Signal Strength; Frequency Modulation; Transmitting Antenna; Radio Transmission

\section{Introduction}

Frequency modulation (FM) is the transmission of information over a carrier wave by varying its frequency while radio wave propagation is the transfer of energy at radio frequency, from the transmitter to the receiver [1],[2]. In FM transmission, the signal strength depicts the amount of energy radiating from the transmitter of a radio station and this is a very significant parameter which characterizes the station's emission [2].

The frequency range of $87.5 \mathrm{MHz}$ to $108.0 \mathrm{MHz}$ are dedicated to FM radio transmission which are propagated through space waves technique which consist of direct and ground reflected waves. As such, ground electrical parameters refractivity, reflectivity, conductivity, permittivity and bulging on the radio path, as well as prevailing meteorological conditions, have glaring impact on the transmitting radio waves [3],[4],[5],[6]. Moreso, signals propagated as space waves are influenced by hills, mountains, terrains, multipath interference, non-line of sight blockage, fading and soil electrical parameters within the propagation path [7],[8].

Gauging the strength of radio signals over a given location is important for determining the quality of service of a broadcast station over such location [9]. It equally plays important roles in the analysis of signal coverage area, estimation of signal interference, frequency re-use, as well as allocation of channel frequency and transmitting power

\footnotetext{
* Corresponding author: UJ Ekah

Department of Physics, Cross River University of Technology, Calabar, Nigeria.

Copyright ( 2022 Author(s) retain the copyright of this article. This article is published under the terms of the Creative Commons Attribution Liscense 4.0.
} 
[10]. It is used in transmission planning, used in the design and analysis of the link budget of a communication system and for coverage determination, since quality coverage is the key goal in broadcasting [11],[12],[13],[14],[15],[16].

Many researchers have conducted various researches to evaluate the coverage of FM signals in various terrains. During these studies, the receiving and transmitting antenna gains, the terrain conditions and the channel characteristic are usually considered [12],[17],[18],[19],[20],[21].

This research investigates the coverage of FM signals of two radio stations in Uyo, Nigeria, using their electric field strength. This result will be useful to the FM stations and RF planners for proper signal transmission, planning and coverage in this region.

\section{Material and methods}

Materials used in this research are a digital spectrum analyzer (GW-INSTEK) GSP-730 with frequency range of $150 \mathrm{MHz}$ - 3GHz, a Yagi antenna, a solar panel, an inverter, a grapher 14 software, a surfer 16 software, a laptop, a USB cord, a Google app and a moving vehicle.

In addition, some transmitter parameters like transmission frequency, maximum transmitter power, operating transmitter power, antenna height and polarization were obtained from the radio stations to aid in this research. This is shown in the table below:

Table 1 FM Transmitter Parameters

\begin{tabular}{|l|c|c|}
\hline \multicolumn{1}{|c|}{ FM Station } & AKBC FM & Passion FM \\
\hline Frequency & $90.5 \mathrm{MHZ}$ & $94.5 \mathrm{MHZ}$ \\
\hline Maximum Transmitter Power & $20 \mathrm{KW}$ & $5 \mathrm{KW}$ \\
\hline Operating Transmitter power & $12 \mathrm{KW}$ & $5 \mathrm{KW}$ \\
\hline Antenna Height Above Sea Level & 960 Feet & 120 Feet \\
\hline Polarization & Omni-directional & Linear \\
\hline
\end{tabular}

With the above listed materials, a signal strength measurement system was set up. A Yagi antenna was attached to the roof of the car at a height of $10 \mathrm{~m}$ along with a solar panel. The solar panel was connected to an inverter to charge the associated battery while the battery was connected to a switch which powers the system. The spectrum analyzer was connected to the laptop through the USB Cord. The laptop has the spectrum analyzer software installed on it to interface the system. At the various study locations, the spectrum analyzer is put $\mathrm{ON}$ along with the laptop. The spectrum analyzer is adjusted to the signal frequencies under investigation and the signal strengths received is saved on the laptop for further analysis.

While taking measurements of the signal strengths from the radio stations at strategic locations, the Google app was simultaneously used in measuring the longitude, latitude, elevation and distance from the reference point (location of transmitting antenna). The locations were chosen based on their importance in Uyo metropolis. Measurement of signal strengths for each location was taken from 8:30 to 18:00 hours to obtain a justifiable inference.

The obtained measurements were analyzed to obtain the average signal strengths for both radio stations in each location. Also, longitude, latitude, distance and elevation of each location taken under consideration was obtained. For ease of location identification, University of Uyo permanent site is denoted as A, University of Uyo annex as B, University of Uyo Town Campus as C, University of Uyo Teaching Hospital as D, Victor Attah Airport as E, Godswill Akpabio Stadium as F, Federal Secretariat as G, Akwa Ibom State Secretariat as H, Shelter Afrique Housing Estate as I, Ibom Specialist Hospital as J, Ibom Plaza as K, Ibom Tropicana as L, Ibom E-Library as M and Ewet Housing Estate as N. Also, distance is denoted as $\mathrm{P}$ and elevation as $\mathrm{Q}$.

For further analysis, grapher 14 and surfer 16 softwares were used for graph and contour plots respectively. A graph of signal strength against LOS distance as well as signal strength against elevation were plotted, accompanied by correlation analysis. This was done to obtain the extent to which LOS distance and elevation affects coverage. 


\section{Results and discussion}

Spatial distribution of FM signals has been studied in Uyo, Nigeria, with emphasis on AKBC and Passion FM with transmitting frequencies of $90.5 \mathrm{MHz}$ and $94.5 \mathrm{MHz}$ respectively. The analyzed signal strengths and their corresponding locations are presented in table 2. For further analysis, grapher 14 and surfer 16 softwares were used for graph and contour plotting as shown in figure 1, figure 2, figure 3 and figure 4 respectively. Furthermore, data obtained were presented as bar charts in figures 5 and 6. Figures 7 and 8 present graphs of signal strength against LOS distance followed by graphs of signal strength against elevation in figures 9 and 10 .

Table 2 Measured Parameters for each Location

\begin{tabular}{|c|c|c|c|c|c|c|}
\hline Location & Longitude & Latitude & $\mathbf{P}(\mathbf{K m})$ & $\begin{array}{c}\mathbf{Q} \\
\mathbf{( K m )}\end{array}$ & \multicolumn{2}{|c|}{$\begin{array}{c}\text { Signal strength } \\
\mathbf{( d B m}\end{array}$} \\
\hline & & & & & $90.5 \mathrm{MHz}$ & $94.5 \mathrm{MHz}$ \\
\hline A & 5.0289 & 7.9789 & 4.60 & 53 & -84.50 & -82.43 \\
\hline B & 5.0425 & 7.9225 & 3.08 & 69 & -83.33 & -82.43 \\
\hline C & 5.0438 & 7.9241 & 3.01 & 67 & -82.24 & -82.79 \\
\hline D & 5.0111 & 7.8608 & 9.78 & 68 & -84.19 & -83.39 \\
\hline E & 4.8714 & 8.0889 & 29.42 & 41 & -89.50 & -88.48 \\
\hline F & 5.4853 & 7.8869 & 8.16 & 72 & -82.82 & -81.90 \\
\hline G & 5.0181 & 7.8864 & 7.26 & 72 & --83.45 & -83.21 \\
\hline H & 5.0228 & 7.9053 & 5.60 & 66 & -84.07 & -86.68 \\
\hline I & 4.9800 & 7.9564 & 10.63 & 56 & -83.49 & -84.45 \\
\hline J & 5.0492 & 7.8828 & 5.08 & 68 & -83.42 & -84.03 \\
\hline K & 5.1833 & 7.9199 & 4.18 & 71 & -83.45 & -83.25 \\
\hline L & 4.9983 & 7.9403 & 8.59 & 57 & -82.58 & -82.48 \\
\hline M & 5.0150 & 7.9128 & 6.17 & 68 & -83.65 & -82.75 \\
\hline N & 5.0139 & 7.9456 & 7.07 & 66 & -81.26 & -80.16 \\
\hline
\end{tabular}

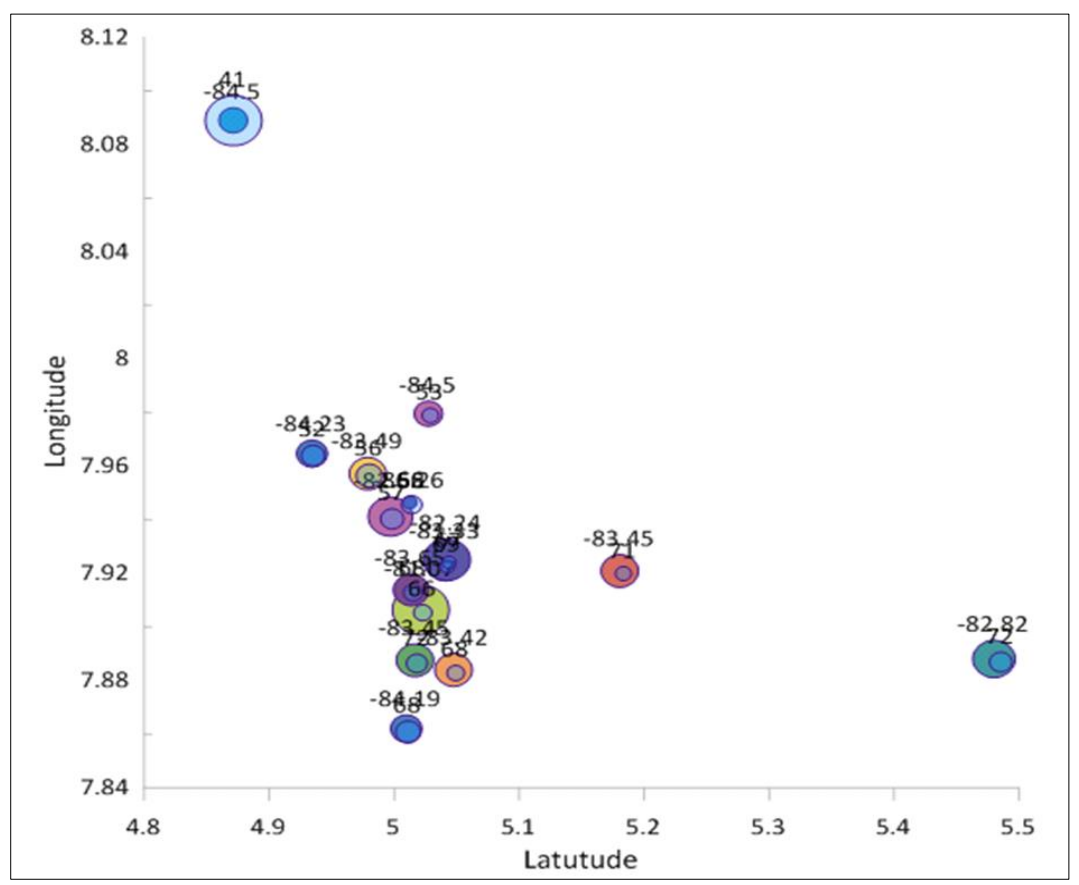

Figure 1 Scattered Signal Strength Plot for AKBC and Passion FM 


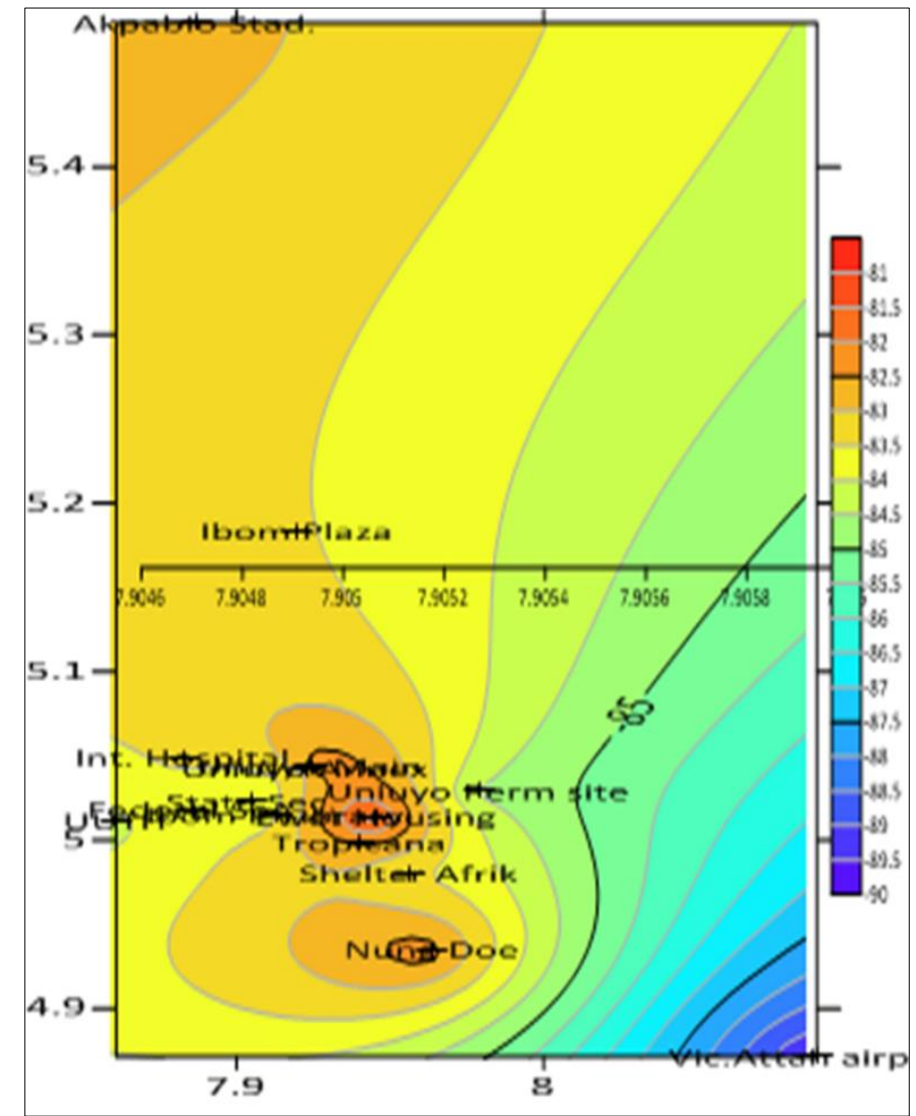

Figure 2 Contour map showing coverage area of AKBC

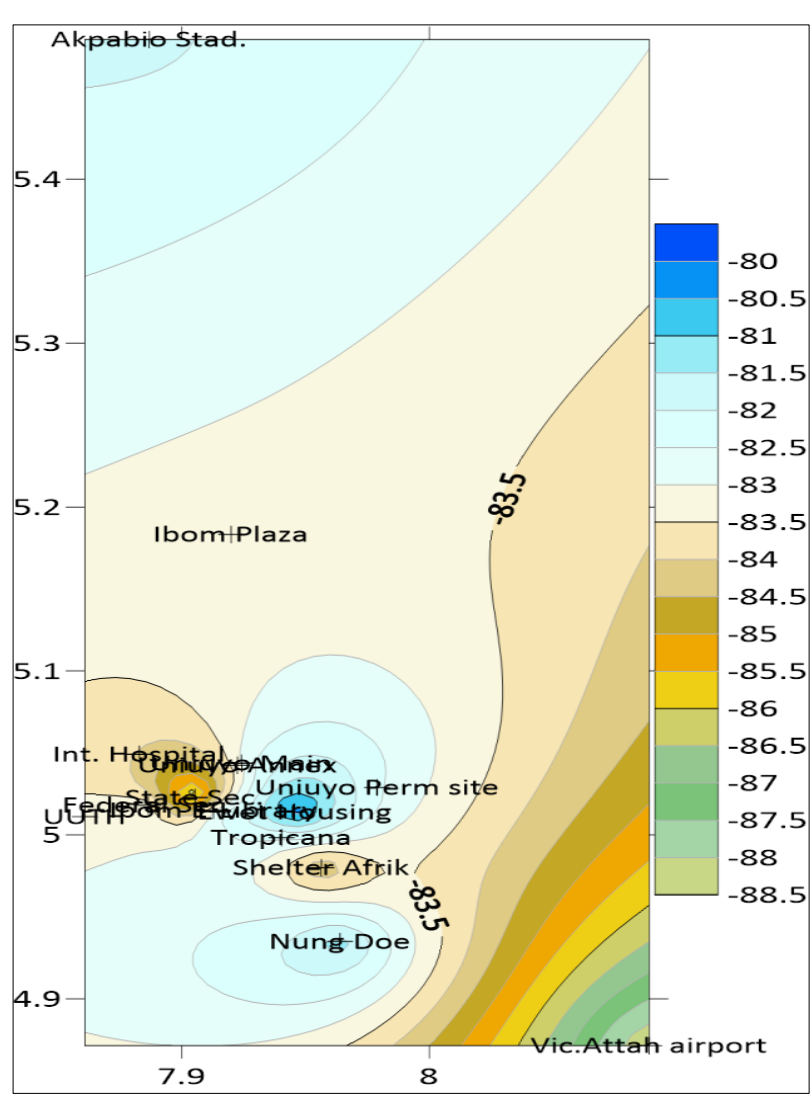

Figure 3 Contour map showing coverage area of Passion FM

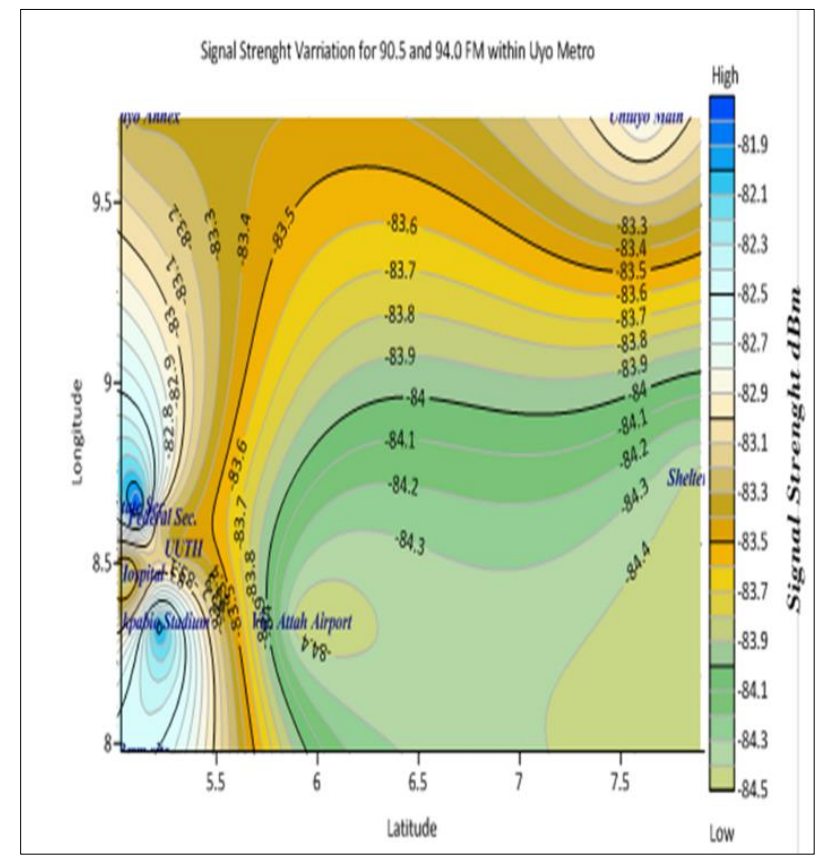

Figure 4 Contour map showing the coverage areas of both stations

The scattered plot in figure 1 and the contour maps in figures 2, 3 and 4 were overlaid with the latitude and longitude of the locations to obtain the accurate position with the measured values and to give a pictorial view of the coverage areas for both radio stations within Uyo metropolis. 


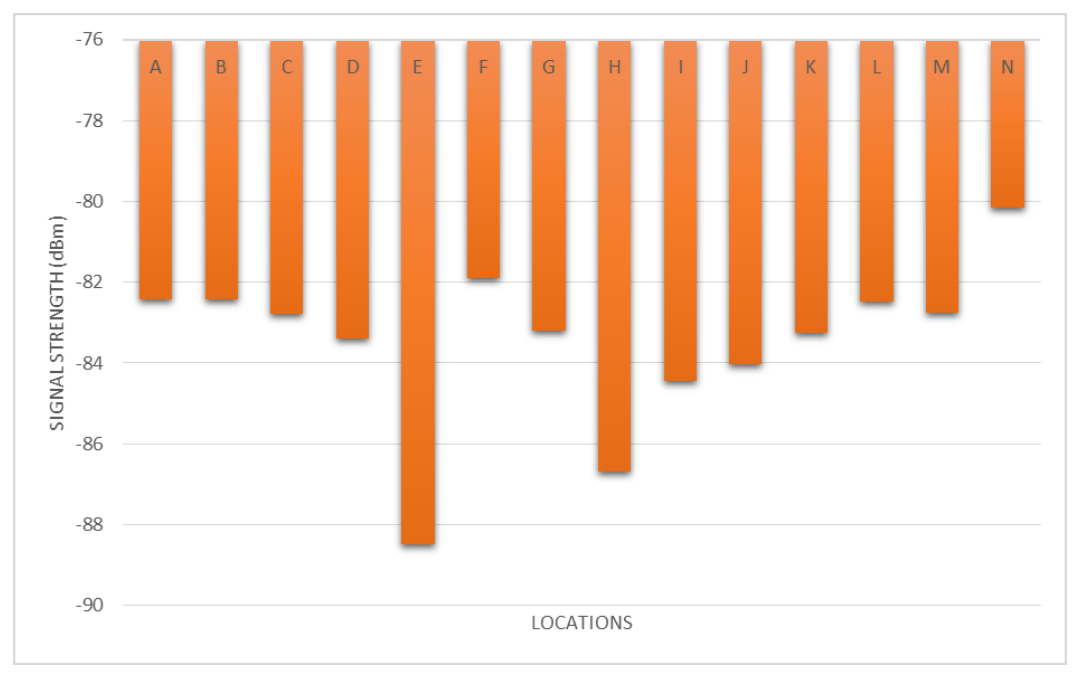

Figure 5 Bar Chart of mean signal strength against location for AKBC

A bar chart of the measured signal strength with respect to their locations is presented in Figure 5 for AKBC. It is deduced that signal strength from $\mathrm{AKBC}$ is higher at locations N, C, L, and F. Location $\mathrm{N}$ having the highest signal strength with location E receiving the least signal strength.

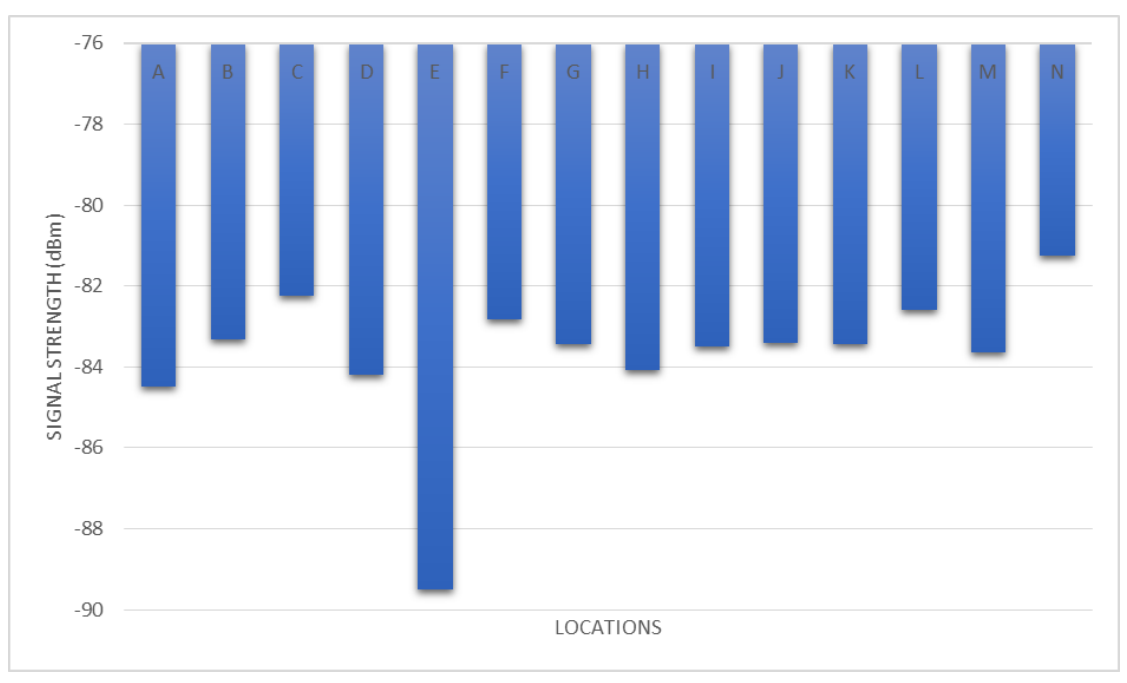

Figure 6 Bar Chart of mean signal strength against location for Passion FM

In figure 6, a bar chart of mean signal strength for Passion FM against the locations is plotted. Locations N, F, A and B is observed to have very good reception. Location $\mathrm{N}$ had the best receiving signal strength while the least receiving signal strength was gotten in location E. 
World Journal of Advanced Engineering Technology and Sciences, 2022, 05(01), 039-046

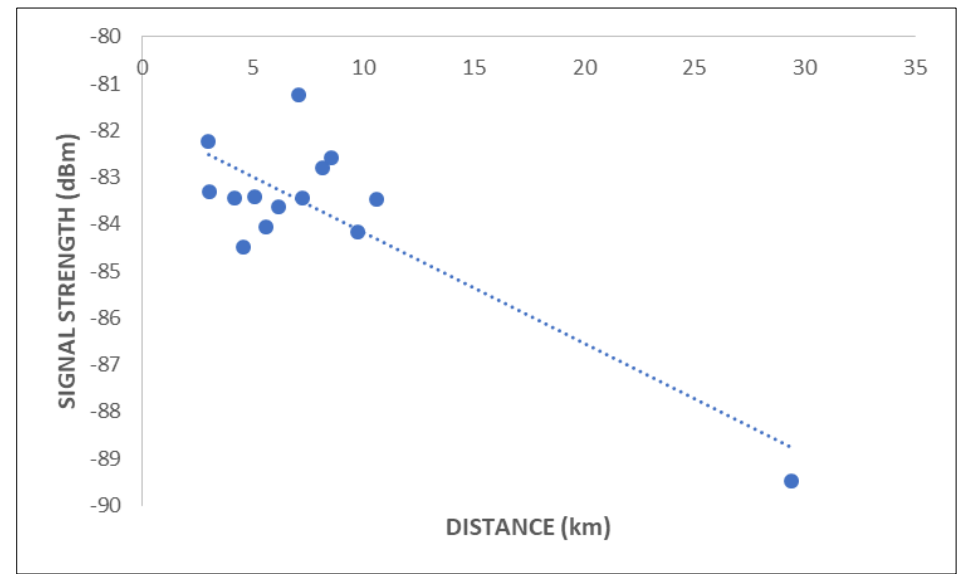

Figure 7 Graph of Signal Strength against Distance for AKBC

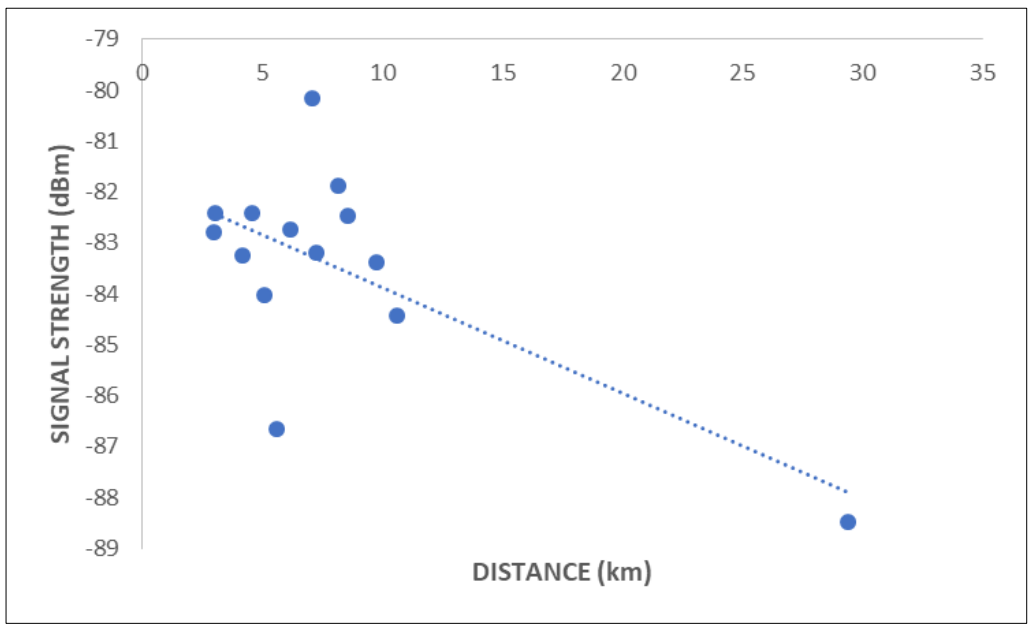

Figure 8 Graph of Signal Strength against Distance for Passion FM

Figure 7 and 8 is a linear plot of signal strength against Line of Sight (LOS) distance for AKBC and Passion FM respectively. A correlation value of -0.84 and -0.67 was obtained in each case. This shows that an increase in distance from the transmitting antenna led to a decrease in signal strength.

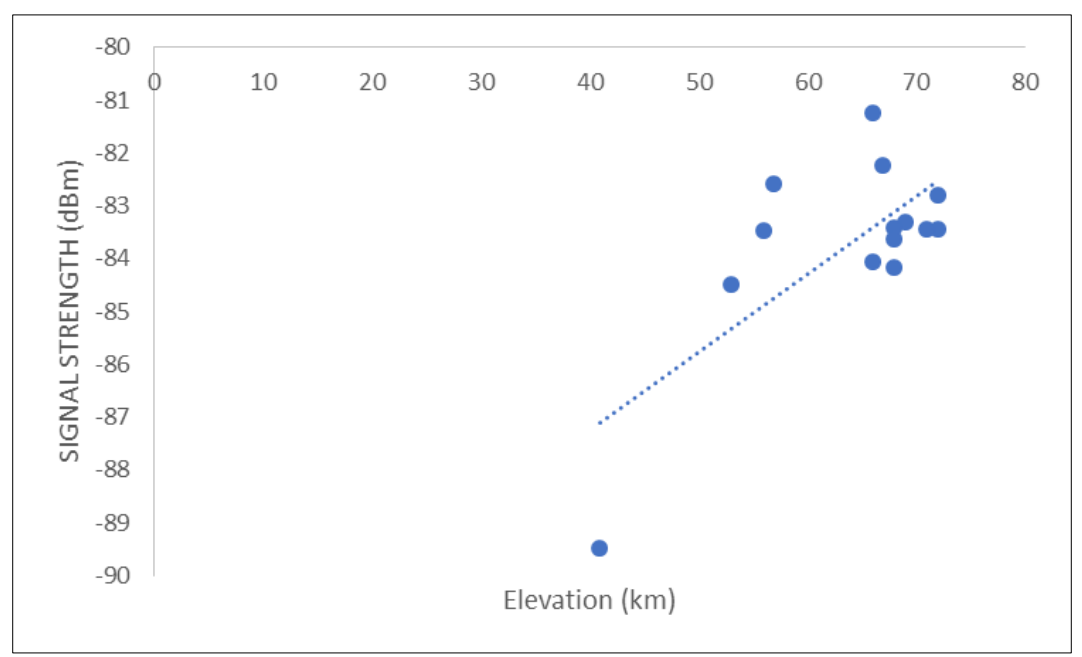

Figure 9 Graph of Signal Strength against Elevation for AKBC 


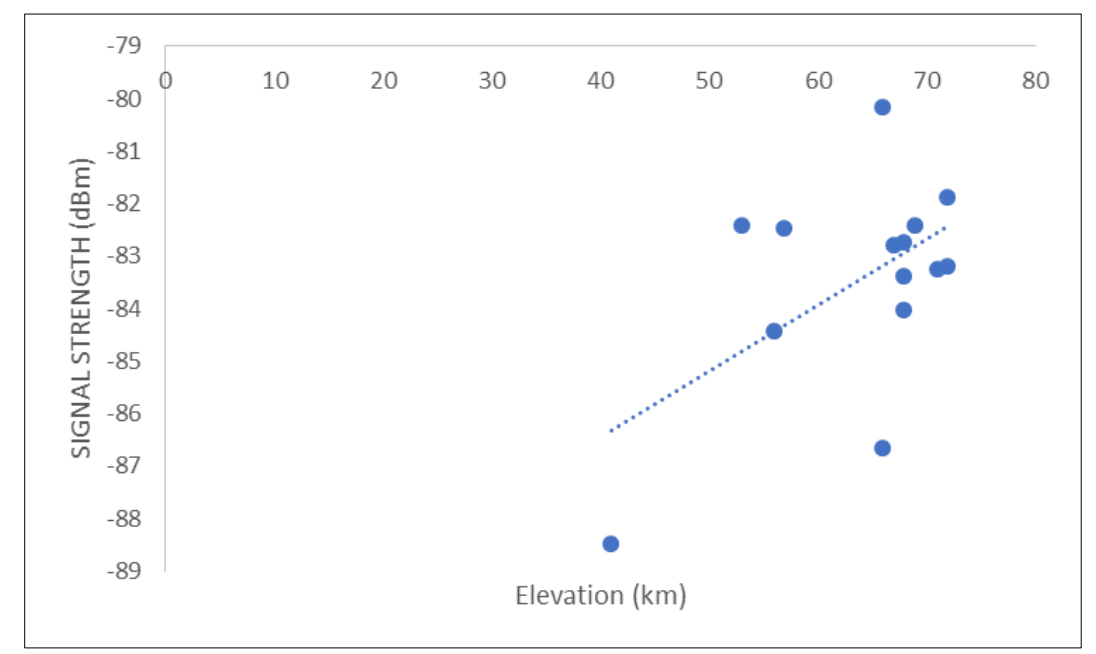

Figure 10 Graph of Signal Strength against Elevation for Passion FM

A further plot of received signal strength against elevation was done in figure 9 and 10, for AKBC and Passion FM respectively. A correlation value of 0.71 and 0.55 was obtained. This shows that an increase in elevation led to an increase in received signal strength.

\section{Conclusion}

Measurement of the signal strengths emanating from $90.5 \mathrm{MHz}$ and FM $94.5 \mathrm{MHz}$ transmitters were carried out with the aim of investigating the coverage extent of both stations at various locations within Uyo metropolis. Results show a decrease in signal strength as LOS distance from the radio transmitter of both radio station increases. It was discovered that elevation had a positive impact on the transmitting signal, as an increase in elevation led to an increase in received signal strength. Moreso, we depicted that the best reception from both stations was obtained at Ewet Housing Estate while the worst reception from both stations was obtained at Victor Attah's Airport. This result will assist radio planners for proper transmission and good signal coverage within Uyo metropolis.

\section{Compliance with ethical standards}

\section{Acknowledgments}

We sincerely thank the management of AKBC and Passion FM for availing us with their transmitter parameters that led to the success of this research.

\section{Disclosure of conflict of interest}

The authors of this article have declared that no competing interest exist.

\section{References}

[1] Oyetunji SA. Determination of propagation path loss and contour map for FUTA FM radio Federal University of Technology, Akure, Nigeria. IOSR Journal of Electronics and Communication Engineering. 2013; 6(3): 4-9.

[2] Olasoji YO, Oyetunji SA. Propagation path loss model for FM radio stations in south west, Nigeria. FUTA Journal of Engineering and Engineering Technology. 2020; 14(1): 8-16.

[3] Hall MPM Barclay LW. Radiowave Propagation, Peter Peregrinus Ltd., London, United Kingdom. $1989 ; 2$.

[4] Ewona I, Ekah U. Influence of Tropospheric Variables on Signal Strengths of Mobile Networks in Calabar, Nigeria. Journal of Scientific and Engineering Research. 2021; 8(9): 137-145.

[5] Iloke J, Utoda R, Ekah U. Evaluation of Radio Wave Propagation through Fo-liage in Parts of Calabar, Nigeria. International Journal of Scientific \& Engineering Research. 2018; 9(11): 244-249. 
[6] Emeruwa C, Ekah UJ. Pathloss Model Evaluation for Long Term Evolution in Owerri. International Journal of Innovative Science and Research Technology. 2018; 3(11): 491-496.

[7] Ajewole MO, Oyedum OD, Moses AS, Eiche JO. Measurement of Electric Field Strength to Determine the Coverage area of VHF/UHF television signals in Niger State, Nigeria. Proceedings of the annual Conference of Nigerian Union of Radio Science, Federal University of Technology, Akure. 2010; 113 -118.

[8] Chomba BK, Konditi DBO, Nyaanga DM, Githeko JM. Effects of varying dis-tance on wireless signal propagation in indoor and outdoor built sites. International Journal of Engineering Research in Africa. 2011; 6: 75-89.

[9] Obi E, Ekah U, Ewona I. Real-Time Assessment of Cellular Network Signal Strengths in Calabar. International Journal of Engineering Sciences \& Research Technology. 2021; 10(7): 47-57.

[10] Haslett C. Essentials of Radio wave Propagation, Cambridge University Press, Cambridge, UK. 2008 ; 1-201.

[11] Georgij L. Determination of the radiated power of radio station through field strength measurement along a route. Proceedings of the 2016 International symposium on electromagnetic compatibility-EMC EUROPE. Wroclaw, Poland. 2016; 4: 5-9.

[12] Akpaida VOA, Anyasi FI, Uzairue SI, Idim AI. Determination of an outdoor path loss model and signal penetration level in some selected modern residential and office apartments in Ogbomosho, Oyo State, Nigeria. Journal of Engineering Research and Reports. 2018; 1(2): 1-25.

[13] Ekah UJ, Emeruwa C. A comparative assessment of GSM and UMTS Networks, World Journal of Advanced Research and Reviews. 2022; 13(1): 187-196.

[14] Ekah UJ, Emeruwa C. Guaging of key performance indicators for 2G mobile networks in Calabar, Nigeria. World Journal of Advanced Research and Reviews. 2021; 12(2): 157-163.

[15] Emeruwa C, Ekah UJ. Investigation of the variability of signal strength of wire-less services in Umuahia, Eastern Nigeria. IOSR Journal of Applied Physics. 2018; 10(3): 11-17.

[16] Ekah UJ, Iloke J. Performance Evaluation of UMTS Key Performance Indicators in Calabar, Nigeria. GSC Journal of Advanced Research and Reviews. 2022; 10(1): 47-52.

[17] Adeniran AO, Olabisi O, Ajao OS. Spatial coverage of FM signal variation measurement and comparison of two major radio stations within Akwa Ibom State. Journal of VLSI Design and Its Advancement. 2020; 3(3): 1-7.

[18] Adegboyega GA, Fapohunda KO, Famoriji JO. Impact of transmission dis-tance on the strength of received signals within the vicinity of four base stations. American Journal of Engineering Research. 2014; 3(1): 272-279.

[19] Chebil J, Lawas AK, Islam MDR. Comparison between measured and pre-dicted path loss for mobile communication in Malaysia. World Applied Sciences Journal, (Mathematical Applications in Engineering). 2013; 21: 123-128.

[20] Famoriji JO, Olasoji YO. Development of radiowave propagation model for hilly areas. International Journal of Electronics and Computer Engineering. 2013; 4(2): 536-539.

[21] Klima J, Marian M. Influence of terrain on multipath propagation of FM sig-nal. Journal of Electrical Engineering. 2005; 56(5-6): 113-120. 